\title{
ALC金NCE
}

\section{PRINCÍPIOS E FATORES MOTIVADORES PARA ADOÇÃO DAS GOVERNANÇAS CORPORATIVA DE TIE DA INFORMAÇÃO}

MOTIVATING PRINCIPLES AND FACTORS FOR THE ADOPTION OF CORPORATE, IT AND INFORMATION GOVERNANCE

\section{PRINCIPIOS Y FACTORES MOTIVADORES PARA ADOPCIÓN DE LAS GOVERNANZAS CORPORATIVAS DE TI Y DE LA INFORMACIÓN}

\author{
ANTONIO CARLOS GASTAUD MAÇADA \\ Doutor \\ Universidade Federal do Rio Grande do Sul - Brasil \\ ORCID: 0000-0002-8849-0117 \\ acgmacada@ea.ufrgs.br
}

\section{RAFAEL ALFONSO BRINKHUES}

Doutor

Instituto Federal de Educação, Ciência e Tecnologia do Rio Grande do Sul - Brasil

ORCID: 0000-0002-9367-5829

rafael.brinkhues@viamao.ffrs.edu.rb

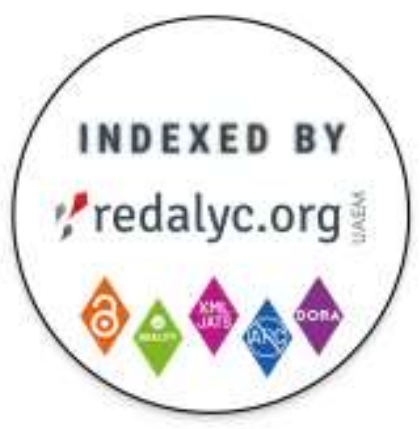

JOSÉ CARLOS DA SILVA FREITAS JR.

Doutor Universidade Federal do Rio Grande do Sul - Brasil ORCID: 0000-0002-9050-1460 freitas1995@gmail.com

TAMARA TEBALDI LAJARA Mestra Universidade Federal do Rio Grande do Sul - Brasil ORCID: 0000-0002-3309-6059 ttlajara@gmail.com

LCENÇA CC BY:

Artigo distribuído Submetido em: 06/09/2018 sob os termos Creative Commons, Aprovado em: 12/04/2019 permite uso e distribuição irrestrita em qualquer meio desde que o autor credite a fonte original.

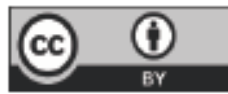




\section{RESUMO}

Essa pesquisa se propõe a analisar os princípios e os fatores motivadores para adoção da governança corporativa, da tecnologia da informação (TI) e da Governança da Informação (GI). Fundamentado na Economia da Informação e na Teoria da Agência, foi realizada a identificação na literatura dos princípios e dos fatores motivadores desses três tipos de governança. Por meio de um estudo de casos múltiplos em três organizações que adotam estruturas de governança corporativa, da TI e da Informação, foi possível analisar esses elementos a partir da perspectiva dos executivos das respectivas áreas das empresas. Com base nos resultados da pesquisa, foi possível realizar um comparativo entre as estruturas de governança dos três casos. Os resultados demonstram que não há uma estrutura ideal para governança, cada caso possui relações únicas, sendo que os casos não apresentaram consenso na relação entre governança de $\mathrm{TI}$ e da Informação. $O$ estudo revela que há uma falta de consenso em relação a dois tipos de governança analisados, TI e $\mathrm{Gl}$, bem como identifica uma negligência em relação aos fatores contingenciais que afetam o ambiente informacional, contribuindo, assim, para o desenvolvimento da literatura, especialmente de $\mathrm{Gl}$, ainda incipiente na pesquisa acadêmica. Para os praticantes, a pesquisa contribui com a comparação e a análise das estruturas de governança, que os auxilia a definirem os elementos mais adequados para cada organização.

Palavras-chave: Governança da Informação. Governança de Tecnologia de Informação. Governança Corporativa.

\section{ABSTRACT}

This paper analyzes the principles and motivating factors in the adoption of Corporate Governance, Information Technology (IT) governance and Information Governance (IG). Based on Information Economics and Agency Theory, the principles and motivating factors of these three types of governance were identified in the literature. Through a multi-case study in three organizations that adopted structures of corporate governance, IT governance and IG, these elements were analyzed from the perspective of the executives of these respective areas of the companies. Based on the results, a comparison was made between the governance structures of these three cases. The results show that there is no ideal structure for governance; each case has its own unique relations, and the cases did not present a consensus in the relationship between IT governance and information. Besides the elements revealed in the case studies, this research adds information on the still incipient literature on the subject in Brazil, and adds empirical research to the world literature. For practitioners, this research contributes with the comparison and analysis of governance structures, which can help them to define the most appropriate elements for each organization.

Keywords: Information Governance. Information Technology. Governance. Corporate Governance

\section{RESUMEN}

El presente artículo se propone analizar los principios y factores motivadores en la adopción del gobierno corporativo, de la Tecnología de la Información (TI) y de la Información (GI). Fundamentado en la Economía de la Información y en la Teoría de la Agencia, se realizó la identificación en la literatura de los principios y factores motivadores de estos tres tipos de gobernanza. A través de un estudio de casos múltiples en tres organizaciones que adoptan estructuras del gobierno corporativo, de la TI y de la Información, fue posible analizar esos elementos desde la perspectiva de los ejecutivos de las respectivas áreas de las empresas. Con base en los resultados de la investigación, fue posible realizar un comparativo entre las estructuras de gobernanza de los tres casos. Los resultados demuestran que no hay una estructura ideal para la gobernanza, cada caso tiene relaciones únicas, siendo que los casos no presentaron consenso en la relación entre gobernanza de la TI y de la información. Además de los elementos revelados en los estudios de casos, la investigación añade informaciones en la aún incipiente literatura sobre el tema en Brasil, y añade una investigación empírica a la literatura mundial. Para los profesionales, la investigación contribuye con la comparación y análisis de las estructuras de gobernanza, que les ayuda a definir los elementos más adecuados para cada organización.

Palabras clave: Gobernanza de la información. Gobernanza de la Tecnología de la Información (TI). Gobierno Corporativo. 


\section{INTRODUÇÃO}

A literatura de Sistemas de Informação (SI) tem apresentado várias pesquisas que combinam os temas Governança Corporativa, Governança de Tecnologia da Informação (TI) e Governança da Informação, buscando identificar os seus antecedentes e as suas possíveis relações (Calder, 2008; Grembergen \& Haes, 2009; 2015; Smallwood 2014; Faria, Maçada \& Kumar, 2017). Tallon, Ramirez e Short (2013) apresentaram os antecedentes da Governança da Informação e Governança de TI e tangenciam as relações com a GC, pois apenas tratam como sua existência baseada na Sarbenes-oxley (1960) e Basileia (2004), o que não é o suficiente para uma análise completa sobre a adoção desses frameworks.

Nesse sentido, a governança corporativa possui escopo mais amplo que as demais, pois engloba "os controles e procedimentos que existem para assegurar que a administração atue em interesse dos stakeholders" (Kanagaretnam, Lobo, \& Whalen, 2007, p. 498) e a governança de TI preocupasse com quem são os responsáveis, quais e como são realizadas e controladas as decisões de forma a garantir a gestão e o uso eficaz da TI (Weill \& Ross, 2006). Assim como a governança corporativa, a governança de TI se concentra em manter a segurança e 0 valor dos negócios das organizações, entretanto, com foco na gestão efetiva dos investimentos e recursos de TI necessários para enfrentar os desafios e aproveitar as oportunidades do mercado (Vatharkar, Gao, \& Fomin, 2018).

Por sua vez, a governança da informação é um framework que auxilia a organização a lidar com o desafio de gerenciar o novo contexto informacional. Segundo Tallon, Ramirez e Short (2013), a literatura apresenta dois objetivos para a governança da informação: (1) para maximizar o valor da informação para a organização, garantindo que a informação é confiável, segura e acessível para a tomada de decisão e (2) para proteger a informação para que o seu valor para a organização não seja diminuído por meio da tecnologia ou erro humano, perda de acesso em tempo útil, uso inadequado ou algum outro erro. A emergência de tecnologias impõe às organizações a necessidade de desenvolver novas habilidades para lidar com o crescimento exponencial no fluxo de informações advindo dessas novas fontes (Bharadwaj, El Sawy, Pavlou, \& Venkatraman, 2013). Essas novas informações tornam a governança da informação uma capacidade crítica para gestores seniores de Tl e de negócios para que as organizações possam se manter competitivas nesse novo contexto informacional (Mikalef, Pappas, Krogstie, \& Giannakos, 2017).

Entretanto, o estudo dos fatores e dos princípios motivadores para a adoção de cada tipo de governança e, em especial, sua relação permanecem pouco explorados, à exceção de Hamacker (2003), que não trabalhou com a governança da informação. No contexto brasileiro, poucos estudos apresentados abordam especificamente a governança da informação (e.g. Faria \& Maçada, 2013). Esse estudo pretende contribuir para os práticos e acadêmicos, respondendo à seguinte questão de pesquisa: Como as organizações relacionam os princípios e os fatores motivadores na adoção da governança corporativa de Tl e da informação?

Os princípios de governança são características identificadas em organizações bem governadas que podem vir a ser aplicados em outras organizações que busquem implantar algum nível de governança (Hamaker, 2003). Já os fatores motivadores são os princípios que não necessariamente permitem a identificação de sua aplicabilidade, mas demonstram os objetivos e as vantagens pelos quais a organização busca ao adotar sua estrutura de governança.

É crescente o número de organizações que adotam de forma mandatória, ou não, a Governança Corporativa, de TI e, mais recentemente, a Governança da Informação (Bala, 2018). Assim, essa pesquisa objetiva analisar os princípios e os fatores motivadores que auxiliam as organizações no processo de adoção destes três tipos de governança.

Para isso, a revisão da literatura apresenta os fundamentos teóricos da economia da informação e da teoria da agência, teorias base para a construção dos conceitos na estrutura de governança. Logo após, apresentam-se as definições das governanças. Em seguida, serão apresentados os procedimentos metodológicos do estudo de casos em três corporações que adotam os três tipos de governança pesquisados, os resultados da análise comparativa entre os casos e as conclusões finais.

\section{REVISÃO DE LITERATURA}

Para analisar a governança da informação, faz-se necessário antes a análise das estruturas de governança de uma organização. A seção iniciará com a governança corporativa e governança de TI e finaliza com a governança da informação. 


\subsection{Governança Corporativa}

Governança corporativa pode ser visualizada como o grande guarda-chuva que abrange a empresa e, segundo Kanagaretnam, Lobo e Whalen (2007, p. 498), ela pode ser definida como "os controles e procedimentos que existem para assegurar que a administração aja em interesse dos stakeholders". Os mesmos autores também escrevem que a governança corporativa visa reduzir a possibilidade que, por outros motivos, a administração se desvie do objetivo de maximizar o valor da empresa.

Gompers, Ishii e Metrick (2003) realizam uma metáfora apresentando a empresa como uma república. Nessa república, os autores dizem que os eleitores são os stakeholders e os governantes são os diretores e a equipe administrativa da empresa. Eles escrevem que os direitos que esses stakeholders têm sobre os governantes são as regras de governança e que, dependendo do número de direitos (ou regras de governança), essa república pode ser uma democracia ou uma ditadura.

Para Bushman e Smith (2001, p. 238), esses controles empresariais são os meios pelos quais os administradores "são disciplinados para agir pelos interesses dos investidores" e que podem ser tanto internos, como um plano de incentivo aos administradores; e externos, como competições no mercado por um produto ou o monitoramento de acionistas.

Para Gompers, Ishii e Metrick (2003, p. 34), a governança corporativa "é fortemente correlacionada com o retorno das ações durante os anos 1990". Ammann, Oesch e Schmid (2011) encontraram resultados em suas pesquisas que indicam que práticas de melhor governança corporativa se refletem, estatisticamente e economicamente, em empresas com o valor de mercado maior. Apesar de pesquisas que ressaltam os benefícios da governança corporativa, há também custos elevados na implantação de governança, como mencionado por Chhaochharia e Laeven (2009). Apesar desses custos, suas pesquisas também chegaram ao resultado que implantação de governança corporativa aumenta o valor de mercado das empresas. Para o IBGC, a governança corporativa tem como finalidade "preservar e otimizar o valor da organização, facilitando seu acesso a recursos e contribuindo para sua longevidade".

Segundo Hamaker e Hutton (2003), governança não é um tema novo, mas se se olhar as páginas de jornais e revistas, obtém-se a justificativa para se verificar os processos de governança nas empresas e, em muitos casos, avançar em mais um degrau no nível de atenção nesta estrutura.

\subsection{Governança de Tecnologia da Informação (Ti)}

Segundo Weill e Ross (2006, p. 8), "a governança determina quem toma decisões". Para esses autores, o setor de TI também necessita determinar quem deve tomar as suas decisões e quais e como tomá-las. Para Sohal e Fitzpatrick (2002), é a governança que responde à questão do que precisa ser realizado com o objetivo de alcançar maiores benefícios para a empresa resultado da maior sinergia da TI com a organização. Weill e Ross $(2006$, p. 8) definem a governança de TI como "a especificação dos direitos decisórios e do framework de responsabilidades para estimular comportamentos desejáveis na utilização de TI". Os mecanismos da Governança de TI devem focar no planejamento e na implementação das capacidades organizacionais e habilidade requeridas para o sucesso na gestão e nos investimentos em recursos de TI para que as organizações consigam atender às necessidades do ambiente competitivo (Grembergen \& De Haes, 2015, 2018).

Segundo Bowen, Cheung e Rohde (2007, p. 192), o que desafia a implantação de governança de TI é o tipo de "independência que o grupo de trabalho tem, o valor da aliança da cadeia e a ambientes competitivos", e para os mesmos autores, é tão desafiador, pois na governança de TI devem ser unidos os conhecimentos únicos de stakeholders e fornecedores de serviços.

É claro que, para qualquer empresa, definir e implantar um modelo completo de governança têm um custo alto e demanda muito tempo. Mas Weill e Ross (2006) expõem que é interessante o investimento, visto que uma estrutura de governança bem implantada alinha as decisões das empresas com os seus objetivos, o que é muito importante especialmente no setor de $\mathrm{TI}$, em que há um valor elevado de investimentos e uma constante substituição de tecnologias, um setor em que uma aquisição errônea pode trazer sérios problemas financeiros a uma empresa. Para Trites (2004, p. 97), com a evolução da importância da área de TI nas empresas, nos últimos anos, as responsabilidades, especialmente dos diretores, evoluíram também "de tentar avaliar o impacto de determinadas tecnologias no negócio para incorporar TI como principal recurso para alcançar os objetivos empresariais". Segundo Bernroider (2008, p. 257), "as atividades de TI são criticamente importantes para todos os aspectos da empresa".

E para Luciano e Testa (2011, p. 245), "esse link estabelecido entre TI e negócio gera resultado a partir do momento em que os objetivos da governança de TI vão sendo alcançados" e esse resultado pode ser expresso com melhora nos índices de rentabilidade, como a pesquisa de Lunardi, Becker e Maçada (2012), que constatou empiricamente que organizações com mecanismos formais de governança de TI mostram melhoras nas suas medidas de rentabilidade. Apesar dessa melhora nos resultados, as empresas ainda parecem não saber qual modelo de 
governança de TI aplicar (Brown \& Grant, 2005). Para Larsen, Pedersen e Andersen (2006, p. 2), as organizações podem "criar seus próprios modelos de governança de $\mathrm{Tl}$, ou adotar padrões que têm sido desenvolvidos e aperfeiçoados através da experiência combinada de milhares de organizações e pessoas". Entre as ferramentas listadas por Larsen, Pedersen e Andersen (2006) estão: COBIT (control objectives for information and related technology), ITIL (information technology infrastructure library), ASL (application services library) e outras.

Demonstrada a importância da governança corporativa e de TI, apresentar-se-á a importância de um conceito, relativamente novo na área acadêmica, mas fundamental para as empresas: A governança da informação.

\subsection{Governança da Informação}

Para Wende (2007), é importante fazer a distinção entre governança da informação e governança de TI. Enquanto a governança de TI lida com os ativos de TI da empresa, a governança da informação envolve os ativos de informação da firma. E a diferença, segundo Khatri e Brown (2010, p. 148), é que "os ativos de TI referem-se às tecnologias (computadores, comunicação e bases de dados) que auxiliam a suportar a automação de tarefas bem definidas, enquanto os ativos de informação (ou de dados) são definidos como fatos que têm valor ou valor em potencial que são documentados". Para Wende (2007), a governança da informação e a governança de TI estão no mesmo nível hierárquico, sendo que as duas devem seguir os princípios de governança corporativa. Um dos modelos de governança de TI, o COBIT, pressupõe que as informações da organização devem ter critérios de controle, que são: "Eficiência, eficácia, confidencialidade, integridade, disponibilidade, conformidade com regulações e confiabilidade" (Faria, 2010, p. 177). Essas são algumas das dimensões da qualidade da informação e envolvem também o compliance da informação, ou seja, ainda que sejam duas estruturas com objetivos e processos diferentes, há uma fronteira entre elas. A governança da informação é uma capacidade crítica para gestores de TI e de negócios para que as organizações possam se manter competitivas nesse novo contexto informacional (Mikalef, Pappas, Krogstie, \& Giannakos, 2017).

\begin{tabular}{|c|c|c|c|}
\hline & Governança Corporativa & Governança de TI & Governança da Informação \\
\hline Princípios & $\begin{array}{l}\text { Direitos dos acionistas } \\
\text { Independência } \\
\text { Responsabilidade e } \\
\text { transparência } \\
\text { Papéis e responsabilidades da } \\
\text { equipe de administração }\end{array}$ & $\begin{array}{l}\text { Alinhamento com governança } \\
\text { corporativa } \\
\text { Fornecer maior valor da TI para } \\
\text { a empresa } \\
\text { Administrar os riscos da TI }\end{array}$ & $\begin{array}{l}\text { Alinhamento com governança } \\
\text { corporativa } \\
\text { Fornecer maior valor da } \\
\text { informação para a empresa } \\
\text { Assegurar a utilização e a } \\
\text { administração correta das } \\
\text { informações }\end{array}$ \\
\hline $\begin{array}{c}\text { Fatores } \\
\text { Motivacionais }\end{array}$ & $\begin{array}{l}\text { Crescimento da complexidade e } \\
\text { na organização } \\
\text { Globalização } \\
\text { Rápido avanço da tecnologia } \\
\text { Aceleramento da tomada de } \\
\text { decisão } \\
\text { Equipes mais proativas } \\
\text { Aumento da competição } \\
\text { Escândalos recentes }\end{array}$ & $\begin{array}{l}\text { Os mesmos da governança } \\
\text { corporativa } \\
\text { Suporte da governança } \\
\text { corporativa } \\
\text { Expansão do papel da TI: nas } \\
\text { iniciativas de estratégia } \\
\text { Expansão do papel da TI: no } \\
\text { conhecimento administrativo } \\
\text { Expansão do papel da TI: } \\
\text { privacidade, segurança e } \\
\text { continuidade } \\
\text { Proliferação de tecnologias do } \\
\text { tipo "solução" }\end{array}$ & $\begin{array}{l}\text { Os mesmos da governança } \\
\text { corporativa } \\
\text { Suporte da governança } \\
\text { corporativa } \\
\text { Roubo e invasão de dados } \\
\text { Má qualidade da informação } \\
\text { Aumento e maior rapidez do } \\
\text { compartilhamento das } \\
\text { informações } \\
\text { Responsabilidades legais das } \\
\text { empresas quanto a informação }\end{array}$ \\
\hline $\begin{array}{c}\text { Influências da } \\
\text { Teoria da Agência }\end{array}$ & $\begin{array}{l}\text { Mecanismos que buscam } \\
\text { minimizar: Custo de agência } \\
\text { Assimetria de informações }\end{array}$ & $\begin{array}{l}\text { Mecanismos que buscam } \\
\text { minimizar: } \\
\text { Custo de agência } \\
\text { Assimetria de informações }\end{array}$ & $\begin{array}{l}\text { Mecanismos que buscam } \\
\text { minimizar: } \\
\text { Custo de agência } \\
\text { Assimetria de informações }\end{array}$ \\
\hline
\end{tabular}

Figura 1. Princípios e Fatores Motivadores da Governança Corporativa, de TI e da informação Fonte: Adaptada de Hamaker (2003, p. 2). 
Para Weill e Ross $(2006$, p. 22), "a informação sempre foi importante nas empresas, mas com os desenvolvimentos tecnológicos dos últimos anos, seu papel e valor mudaram significantemente". Além dos avanços da tecnologia, a importância do cuidado com a informação aumentou também devido às altas perdas monetárias causadas, em grande parte, por problemas no controle da informação, como nos escândalos citados na introdução do projeto de dissertação. A governança da informação é necessária, pois "a governança deve auxiliar as empresas a aprender de modo que elas parem de cometer os mesmos erros repetitivamente" (Weill \& Roos, 2009, p. 97). A habilidade para identificar as necessidades informacionais internas e externas é mandatória em um ambiente competitivo com intenso fluxo informacional, é nesse contexto que a Governança da Informação desempenha um papel significante (Coyne, Coyne, \& Walker, 2018).

Governança pode ser um termo já comum hoje (Kooper, Maes \& Lindgreen, 2011), mas depois da introdução dessa estrutura, são necessários mais detalhes sobre as diferenças entre governança corporativa, de TI e da informação. Para auxiliar na diferenciação entre os tipos de governança, ver Quadro 1, adaptado de Hamaker (2003).

Dentro dessa estrutura de governança, pode-se visualizar um refinamento no controle, facilitando a administração de responsabilidades e tarefas pelo conselho de administração e diminuindo os riscos de problemas na empresa. Quando Hamaker (2003) propôs esse quadro, ele envolvia governança corporativa, de TI e empresarial, governança que foi substituída pelos autores por dados referentes à governança da informação e também foram reduzidos os pontos abordados. Outra questão importante é a influência da teoria da agência, quando se trata de governança. A governança corporativa é um conjunto de mecanismos que busca minimizar o custo de agência, segundo autores como Hutchinson e Gul (2004).

\section{MÉTODO DE PESQUISA}

Esta seção trará definições e razões para a escolha da pesquisa qualitativa, após o detalhamento sobre estudo de casos múltiplos e seguindo com explicações sobre cada etapa do desenho de pesquisa. Segundo Yin (2005), o fato de a pesquisa focalizar um acontecimento contemporâneo (dado que a adoção - especialmente da governança da informação - pelas organizações ocorreu pelo crescimento exponencial de informações disponibilizadas pela emergência de novas tecnologia) resultou na estratégia de pesquisa estudo de caso ser a mais apropriada para a pesquisa.

Oliveira, Maçada e Goldoni (2009, p. 36) recomendam o estudo de caso para obter "uma visão detalhada de um fenômeno, incluindo seu contexto", o que vai ao encontro dos objetivos dessa pesquisa. Nessa pesquisa, os estudos de casos são classificados como descritivos.

\subsection{OBJETIVOS, UNIDADE DE ANÁLISE E PROTOCOLO DO ESTUDO DE CASOS MÚLTIPLOS}

As unidades de análise pesquisadas são as organizações: um banco, um hospital e uma indústria. Essa seleção por máxima variação ou heterogeneidade tem como resultado descrições detalhadas de cada caso e descoberta de padrões que atravessem as diferenças entre os casos (Patton, 2002). Para Yin (2005), essa lógica de seleção é de replicação teórica, em que se conduzem estudos nos casos em que se preveem resultados contrastantes. Na seleção por máxima variação, buscaram-se segmentos econômicos com diferentes necessidades de informação e diferentes niveis de investimento em tecnologia da informação. A seleção das empresas para os casos foi realizada por conveniência, mas buscando que as mesmas fossem representativas do seu segmento econômico (Vergara, 2009).

$O$ protocolo de estudo de caso dessa pesquisa é formado por: objetivos; um plano de coleta de dados, com as atividades a serem realizadas em cada caso; as fontes de informações a serem pesquisadas; 0 instrumento do estudo de caso, os conceitos dos principais termos utilizados no instrumento de pesquisa e os softwares a serem utilizados, bem como o tipo de análise a ser realizado. 0 protocolo foi validado por duas especialistas, doutoras em Administração, que publicaram artigos sobre o tema utilizando estudos de casos e a técnica de análise de conteúdo. Após a validação, 0 protocolo foi aplicado no estudo de caso piloto e mostrou-se adequado para os objetivos estipulados na pesquisa. 0 estudo do caso piloto em sua análise de categorias revelou 21 categorias iniciais. Essas categorias foram classificadas em categorias finais, que foram definidas a priori. As categorias iniciais serão consideradas elementos das dimensões (categorias finais estudadas). 


\subsection{COLETA DE DADOS}

A coleta de dados foi realizada por meio de dados primários como entrevista semiestruturada, observação direta e dados secundários com análise documental de documentos internos da organização e das reportagens em jornais e revistas. Para Petty, Thomson e Stew (2012), essas três fontes de dados são as mais comuns quando se busca aprofundar o entendimento do estudo de caso.

Entrevistou-se uma pessoa por vez e de forma semiaberta, ou seja, uma "série de perguntas abertas, feitas verbalmente em uma ordem prevista, mas na qual o entrevistador pode acrescentar perguntas de esclarecimento" (Laville \& Dionne, 1999, p. 188). As entrevistas foram realizadas pessoalmente e 0 áudio foi gravado em aparelho digital, com a autorização dos entrevistados, com transcrição posterior. Houve a observação direta, ou seja, apenas se observou 0 fenômeno sem interferência no ambiente, e foram utilizadas como complemento as entrevistas (Yin, 2005). A triangulação das fontes de dados se completa com o uso de documentos, fornecidos pelas empresas e também pesquisados em jornais, revistas e em meio on-line.

Para a seleção dos entrevistados, utilizou-se a técnica snowball ou bola de neve. Essa técnica é utilizada em pesquisas qualitativas e é indicada para quando a seleção randômica é de difícil realização (Biernacki \& Waldford, 1981), como é o caso dessa pesquisa. Assim, a técnica de bola de neve proporciona a seleção adequada dos entrevistados, dado que o primeiro entrevistado, que conhece a organização em que trabalha, poderá indicar pessoas que agreguem informações relevantes à pesquisa (Patton, 2002). Nessa pesquisa se estipulou o mínimo de três entrevistas em cada caso e a definição do máximo de entrevistados foi a saturação das informações. Ou seja, quando as informações advindas das entrevistas se tornaram redundantes. Assim, no Quadro 2 pode se ter um resumo dos entrevistados de cada caso.

\begin{tabular}{|c|c|c|c|c|}
\hline & $\begin{array}{l}\text { Segmento } \\
\text { Econômico }\end{array}$ & Entrevistados & Formação & $\begin{array}{l}\text { Período na empresa/No } \\
\text { cargo }\end{array}$ \\
\hline \multirow[t]{3}{*}{ Caso A } & \multirow{3}{*}{$\begin{array}{l}\text { Indústria } \\
\text { (sistemas } \\
\text { eletrônicos) }\end{array}$} & Gerente de TI & $\begin{array}{llll}\begin{array}{l}\text { Especialização } \\
\text { serviços }\end{array} & \text { em marketing } & \text { de } \\
\end{array}$ & 10 meses/10 meses. \\
\hline & & Coordenador da qualidade & $\begin{array}{l}\text { Especialização em gestão de projetos e } \\
\text { gestão de desenvolvimento de produtos }\end{array}$ & 3 anos/2 anos. \\
\hline & & $\begin{array}{l}\text { Analista de planejamento e } \\
\text { controle }\end{array}$ & Especialização em finanças & 10 meses/10 meses. \\
\hline \multirow[t]{3}{*}{ Caso B } & \multirow{3}{*}{$\begin{array}{l}\text { Financeiro } \\
\text { (Banco) }\end{array}$} & Gerente de Sistemas & Especialização em informática & 39 anos/20 anos. \\
\hline & & $\begin{array}{l}\text { Gerente executivo (Gerente } \\
\text { de governança de } \mathrm{TI} \text { ) }\end{array}$ & Especialização em governança de TI & 33 anos / 2 anos. \\
\hline & & $\begin{array}{l}\text { Gerente Executivo (Gerente } \\
\text { do ambiente informacional) }\end{array}$ & Especialização em TI & 30 anos/4 meses. \\
\hline \multirow[t]{3}{*}{ Caso C } & \multirow[t]{3}{*}{$\begin{array}{l}\text { Hospitalar } \\
\text { (Hospital) }\end{array}$} & $\begin{array}{l}\mathrm{ClO} \text { (Chief Information } \\
\text { Officer) }\end{array}$ & $\begin{array}{l}\text { Especialização em Qualidade } \mathrm{e} \\
\text { Administração hospitalar }\end{array}$ & 14 anos/5 anos. \\
\hline & & $\begin{array}{l}\text { Assessor da vice-presidência } \\
\text { administrativa }\end{array}$ & Mestrado em Administração & 24 anos/8 anos. \\
\hline & & Coordenador administrativo & $\begin{array}{lll}\begin{array}{l}\text { Especialização em } \\
\text { hospitalar }\end{array} & \text { administração } \\
\end{array}$ & 7 anos/10 anos. \\
\hline
\end{tabular}

Figura 2. Entrevistados na Pesquisa

Fonte: Elaborada pelos autores (2018).

Para efeito de análise, que será detalhada na próxima seção, os entrevistados foram codificados como E1A para 0 primeiro entrevistado do caso $A, E 2 A$ para o segundo e E3A para o terceiro. A mesma estrutura foi utilizada nos casos $B$ e C.

\subsection{PREPARAÇÃO E ANÁLISE DOS DADOS}

As entrevistas foram analisadas por meio da técnica de análise de conteúdo, mais especificamente por meio da análise temática ou categorial. Visando à sistematização da análise de conteúdo, foi realizado um referencial ou roteiro de codificação. Para a categorização adequada dos dados, foram seguidas as quatro regras para definição das unidades de categorização, a regra da exaustividade, a regra da representatividade, da homogeneidade e da pertinência (Franco, 2008). Todas se relacionam ao corpus, que significa "o conjunto dos documentos tidos em conta para serem submetidos aos procedimentos analíticos" (Bardin, 2004, p. 90). 
Para auxiliar na análise de conteúdo, foi utilizado o software MAXQDA® no processo de codificação. Segundo Bauer (2002, p. 211), esse tipo de software "comporta a etiquetação, a codificação e a indexação de textos, dando conta por isso da segmentação, ligação, ordenação e reordenação, estruturação e a busca e reapresentação de textos para fins de análise". Ou seja, o software auxiliou na marcação, na contagem, na representação em gráficos e visualização, mas não na criação das categorias e classificação dos elementos nas mesmas.

Na sequência, serão realizadas a análise e a discussão dos resultados obtidos por meio dos estudos de caso e será realizada uma comparação entre eles.

Para a análise do caso $\mathrm{A}$, foram pesquisadas reportagens disponíveis na internet sobre a organização, o próprio site, os documentos fornecidos pela organização (organogramas da empresa, código de ética, apresentações realizadas para novos funcionários), a observação direta (realizada em três ocasiões, totalizando aproximadamente sete horas na empresa) e as três entrevistas. No caso B, os entrevistados apresentaram documentos internos da organização, um deles realizado em conjunto com uma consultoria externa, e outros documentos públicos, presentes no site do caso $\mathrm{B}$, foram consultados, como exemplos: o demonstrativo de resultados financeiros e o histórico da instituição. No caso $\mathrm{C}$, foi realizada uma observação direta (totalizando 4 horas de observação do caso $\mathrm{C}$ ). Alguns entrevistados mostraram relatórios, particularidades e indicadores presentes no sistema de Business Intelligence (BI) da organização. Além disso, foram pesquisados documentos internos, disponíveis no site da instituição, bem como reportagens de jornais e revistas sobre a instituição.

\section{ANÁLISE E DISCUSSÃO DOS RESULTADOS}

A apresentação, bem como a análise dos casos, será realizada individualmente pelos casos dada a máxima heterogeneidade já mencionada na seção anterior. Essa análise abordará as categorias relacionadas às três governanças pesquisadas (corporativa, de TI e da informação), apresentará os fatores motivadores e princípios identificados.

\subsection{Estudo do Caso A}

O caso foi realizado em uma empresa de sistemas eletrônicos, líder na fabricação de hardware e software em aviônica (sistemas eletrônicos para aviação) no Brasil. Atua nos segmentos de defesa, espaço, segurança e logística. Em 2001, foi adquirida por um grupo internacional. A empresa contava com cerca de 280 funcionários em 2016. A matriz do caso $A$ está entre as 50 maiores empresas do mundo no setor aeroespacial.

Para a análise da governança corporativa, de Tl e da informação, as dimensões foram reunidas conforme Quadro 3, em como estão dispostos os princípios e os fatores motivadores do caso A. Como pode ser visualizado no Quadro 3, os principais princípios da estrutura de governança do caso A são a transparência e a prestação de contas. Os dois elementos também são fatores motivadores, visto que, no caso A, agregam benefícios para os investidores, clientes e funcionários.

\begin{tabular}{|l|l|l|l|}
\hline & Governança Corporativa & Governança de TI & Governança da Informação \\
\hline Princípios & $\begin{array}{l}\text { Transparência } \\
\text { Prestação de contas }\end{array}$ & $\begin{array}{l}\text { Alinhamento com governança } \\
\text { corporativa } \\
\text { Transparência } \\
\text { Prestação de contas }\end{array}$ & $\begin{array}{l}\text { Alinhamento com governança } \\
\text { corporativa } \\
\text { Transparência } \\
\text { Prestação de contas }\end{array}$ \\
\hline $\begin{array}{l}\text { Fatores } \\
\text { Motivadores }\end{array}$ & $\begin{array}{l}\text { Transparência } \\
\text { Prestação de contas } \\
\text { Exigências da matriz }\end{array}$ & $\begin{array}{l}\text { Transparência } \\
\text { Prestação de contas } \\
\text { Apoio à informação } \\
\text { Apoio ao negócio } \\
\text { Busca por melhorias no processo } \\
\text { Continuidade da TI }\end{array}$ & $\begin{array}{l}\text { Transparência } \\
\text { Prestação de contas } \\
\text { Apoio ao negócio } \\
\text { Apoio ao processo decisório } \\
\text { Melhorias no controle da } \\
\text { informação } \\
\text { Definições de direito decisório }\end{array}$ \\
\hline
\end{tabular}

Figura 3. Elementos resultantes das entrevistas com executivos do caso $\mathrm{A}$ Fonte: Elaborada pelos autores (2018). 
Bhatt, Hope e Kang (2006) evidenciaram a relação próxima entre governança corporativa e transparência nas informações financeiras. Já no caso $A$, há um desejo que a transparência envolva todo 0 ambiente informacional da organização e não apenas como um princípio da governança corporativa. A transparência está presente na literatura de governança da informação também, segundo Datskovsky (2009).

No caso A, identificou-se o elemento de código de ética na dimensão da governança corporativa. Segundo Cherman e Tomei (2005), os códigos de ética organizacionais mediam os conflitos de interesses dentro da organização e são utilizados como guias de comportamento. $O$ código de ética do caso $A$ expõe princípios para a governança corporativa da organização, mas como apenas um entrevistado estava ciente do mesmo, esses princípios não foram adicionados à análise do caso. Para atingirem esses objetivos, os códigos de ética precisam do apoio de um programa de ética que inclua orientação aos funcionários e que seja construído coletivamente (Cherman \& Tomei, 2005). Logo, baseado na literatura, sugerem-se mais treinamentos e divulgação do código de ética para orientação aos funcionários do caso $A$.

No elemento de apoio à informação, houve uma separação entre as áreas de negócio e o departamento de $\mathrm{Tl}$, em que o setor de TI não fez observações relativas a esse elemento. Essa desatenção do setor de TI com o ambiente informacional é uma das razões para se diferenciar governança da informação e governança de TI. A governança da informação responde às demandas de todo o ambiente informacional da organização e não apenas da área de TI.

Citado na revisão da literatura e suportado na descrição do caso $\mathrm{A}$, a governança da informação, para Kooper, Maes e Lindgreen (2011) e Wende (2007), envolve a definição de direitos decisórios para a informação. Direito decisório, segundo Weill e Ross (2004), pode ser conceituado como a definição de quem tem o direito à tomada de decisão e de quem pode contribuir para essa tomada de decisão. Ou seja, o controle de responsabilidade nas diversas tomadas de decisão da organização. A falta dessa definição dos direitos decisórios pode ser analisada nos trechos das falas dos entrevistados a seguir:

Eu acho também que deveria ter níveis de delegação e eu acho que para isso que serve a governança (E3A).

Não tem, cada um faz o seu. Não tem uma gestão [das informações] (E1A).

Eu diria assim, que o gestor responsável, que sabe que tem a responsabilidade, principalmente com a parte externa de fornecer a informação é tudo cabe a ele, se ele não fizer, se ele não montar ali no setor dele um processo que garanta, daí, ninguém vai saber se ele tá enviando ou não [as informações] (E2A).

Apesar do controle das informações ser realizado de forma informal no caso $A$, não se observa um planejamento das informações, nem efetuado de forma informal. As ações referentes à informação no caso $A$ são realizadas de acordo com a urgência do assunto, "mas de uma forma geral a gente vai a reboque, (...) não para pensar, para planejar" (E1A), e do impacto financeiro que terão na organização, "então, é terrível, ninguém entra no mérito se a gente pode ganhar mais do que isso, ninguém quer pagar multa, pagar multa é uma coisa horrível, né? Quem define o que é importante é 0 tamanho da multa" (E1A).

Outro elemento interessante é o de apoio ao processo decisório. Thomas (2006) utiliza o conceito de tomada de decisão na governança de dados, como surgiu no caso A, "para mim (...) a governança da informação ela é essencial em qualquer processo decisório" (E2A)

Analisando a descrição das três dimensões da governança da informação, percebe-se a utilização do termo "quebra-cabeças" para descrever o ambiente informacional do caso A, metáfora utilizada pelo entrevistado EA3: "algumas informações ficam na mão de alguns, e às vezes, a maioria das pessoas para fazer o seu próprio trabalho acaba tendo que ter uma espécie de um quebra-cabeça". Isso pode indicar uma baixa percepção do valor da informação. Como evidenciado na literatura, "não há excesso de informação, mas muitos fragmentos contraditórios e não integrados de informação" (Cooney, 1991, p. 184).

\subsection{Estudo de Caso B}

$O$ caso $B$ é de uma instituição bancária, de economia mista. É um banco reconhecido mundialmente, na lista de 2019 das 500 marcas bancárias mais valiosas (Brand Finance, 2019). Além disso, premiada internacionalmente em tecnologia bancária. Contava com um quadro de mais de treze mil colaboradores em 2018, é listado no nível 1 de governança corporativa da Bovespa. 
A análise do caso $B$, um banco, revelou vários elementos, apresentados a seguir no Quadro 4. Os resultados das entrevistas com os executivos no caso $A$ são a transparência e a prestação de contas. $E$ os dois elementos também são fatores motivadores, visto que, no caso $\mathrm{A}$, agregam benefícios para os investidores, clientes e funcionários.

\begin{tabular}{|c|c|c|c|}
\hline & Governança Corporativa & Governança de TI & Governança da Informação \\
\hline Princípios & $\begin{array}{l}\text { Transparência } \\
\text { Prestação de contas } \\
\text { Responsabilidade corporativa }\end{array}$ & $\begin{array}{l}\text { Alinhamento com governança } \\
\text { corporativa } \\
\text { Transparência } \\
\text { Prestação de contas } \\
\text { Responsabilidade corporativa }\end{array}$ & $\begin{array}{l}\text { Alinhamento com governança } \\
\text { corporativa } \\
\text { Transparência } \\
\text { Prestação de contas }\end{array}$ \\
\hline $\begin{array}{l}\text { Fatores } \\
\text { Motivadores }\end{array}$ & $\begin{array}{l}\text { Transparência } \\
\text { Prestação de contas } \\
\text { Exigências de órgãos } \\
\text { públicos/reguladores } \\
\text { Exigências internas/padrões } \\
\text { Estrutura organizacional } \\
\text { Gestão de riscos } \\
\text { Busca por melhores indicadores }\end{array}$ & $\begin{array}{l}\text { Transparência } \\
\text { Prestação de contas } \\
\text { Exigências de órgãos } \\
\text { públicos/reguladores } \\
\text { Exigências internas/padrões } \\
\text { Estrutura organizacional } \\
\text { Gestão de riscos } \\
\text { Apoio ao negócio } \\
\text { Apoio à informação } \\
\text { Melhorar a gestão de pesquisa } \\
\text { Melhorar a gestão de projetos } \\
\text { Melhorar a gestão de contratos }\end{array}$ & $\begin{array}{l}\text { Transparência } \\
\text { Prestação de contas } \\
\text { Exigências de órgãos } \\
\text { públicos/reguladores } \\
\text { Exigências internas/padrões } \\
\text { Estrutura organizacional } \\
\text { Monitoramento da informação } \\
\text { Gestão de riscos } \\
\text { Apoio ao negócio } \\
\text { Apoio à decisão } \\
\text { Melhorar o envolvimento de } \\
\text { informação com outras áreas do } \\
\text { negócio } \\
\text { Criação de políticas e normas }\end{array}$ \\
\hline
\end{tabular}

Figura 4. Elementos resultantes análise do caso $B$

Fonte: Elaborada pelos autores (2018).

A conformidade com as exigências legais incentiva os elementos da transparência e da prestação de contas, revelando-se como princípios da estrutura de governança corporativa do caso $B$. A responsabilidade corporativa também pode ser explicada pelo Acordo Basiléia II, afinal, quanto melhor for a gestão de riscos da organização, mais capital a instituição financeira terá disponível o Novo Acordo, ou Basiléia II (Mendonça, 2004). De acordo com Carvalho e Caldas (2006), o Basiléia II tem como principal modificação do Acordo a possibilidade de a instituição financeira adequar essa avaliação de risco de forma adequada aos ativos que possui, acrescentando ao primeiro acordo: uma supervisão bancária (instituição reguladora dos bancos) e a transparência ao mercado.

$\mathrm{O}$ gerente de governança de $\mathrm{TI}$ ressaltou pontos relevantes para a responsabilidade corporativa, como o fato de que o caso B está se preparando para obter e armazenar informações mais detalhadas sobre empréstimos, por exemplo: qual é a finalidade do empréstimo, visto que "está começando a ter um entendimento que o banco é corresponsável pelo que o cara faz com esse dinheiro que foi emprestado" (E2B). Essas práticas têm como objetivo atender a futuras exigências de órgãos públicos e reguladores e exigências atuais de grandes acionistas, alertando que "isso, não é uma coisa bonita e teórica, são situações que começam a ser acenadas [no mercado financeiro]" (E2B).

Logo, a gestão de riscos também é fator motivador para toda a estrutura de governança do caso $B$, bem como para a sua estrutura organizacional do caso $B$, afinal, conforme mencionado pelos entrevistados, as exigências de órgãos, como o Conselho Monetário Nacional (CMN) e o Banco Central (BACEN), fornecem os requisitos para a instituição de uma entidade financeira. Além da estrutura organizacional da governança corporativa, a estrutura organizacional da TI também é motivadora da governança de TI. Dado que o setor foi criado como uma empresa limitada, há um histórico de uma independência na gestão, tornando naturais os elementos de governança de TI dentro do setor.

$\mathrm{O}$ apoio ao negócio como um dos norteadores da governança de TI e da informação também pode ser compreendido pela descrição do caso B. Há uma dependência entre a TI e o negócio do banco, "qualquer processo que tu possas querer saber do banco tu vai ver que a TI apoia e de certa forma tudo começa por ela e termina nela" (E1B).

$\mathrm{Na}$ dimensão de governança da informação, podem-se destacar os elementos: apoio ao negócio, controle da informação e direitos decisórios, políticas e normas, bem como o envolvimento com as áreas de negócio e a estrutura organizacional. Esses dois últimos revelam-se no caso B por já haver um modelo de governança da informação em implantação na organização, inclusive uma gerência dedicada. Importante ressaltar que esse foi o modelo de governança da informação adotado neste caso, mas Weber et al. (2009) e Panian (2010) citam que o modelo de governança não é 
exclusivamente único, dado que são diferentes os fatores contingências, os papéis e as responsabilidades quanto à informação de cada organização, assim cada organização deve analisar o modelo apropriado para o seu ambiente informacional.

No modelo adotado pelo caso $B$, há um elemento de políticas e normas dentro do framework de governança da informação. Para Panian (2010), estabelecer e incentivar políticas e processos quanto à informação é fundar a base da governança da informação. Segundo os entrevistados, existem normas e políticas referentes à informação, mas com a nova gerência do ambiente informacional há a perspectiva de aumentar a amplitude destas, podendo ser exemplificado pelo comentário de E3B: "existem [políticas], mas elas vão crescer e ser mais implantadas".

Outro elemento revelado em governança da informação é informação no processo decisório. Similar à metáfora empregada por Davenport (2004), em que a tubulação de água é a TI e a água é a informação, E2B utiliza uma metáfora em que a informação é uma arma e o bandido é o negócio: "a TI, que é uma parte mais técnica, tem condições de se estar tomando esse pé, mas a gente vai ter a arma e não vai ter o bandido, a gente tem que pegar essa arma e entregar para o banco e dizer 'olha, agora vocês têm o potencial'". Esse elemento é exigido até por órgãos reguladores e de auditoria, dado que é exigido demonstrar as evidências da tomada de decisão, e como mencionado por E2B: "tu tem que saber o porquê daquilo baseado em evidências e as evidências seriam as informações".

Ainda, no caso $B$, que evidenciou uma busca por informações mais detalhadas sobre os clientes para a tomada de decisão, vale destacar que a gestão de dados não estruturados é percebida como uma possível fonte de informações para simulações de risco, já que algumas áreas do banco já as utilizam. A gestão desses dados também é uma das atribuições da governança da informação, segundo E2B: "esta área acho que ela vai começar a mapear o que a gente tem estruturado, o que é necessário e aquele gap do que é necessário ver se está no mundo estruturado e não estruturado".

\subsection{Estudo de Caso C}

$\mathrm{O}$ caso $\mathrm{C}$ foi realizado em uma instituição hospitalar pública e universitária, localizada em Porto Alegre com mais de sete mil funcionários e em média 770 mil consultas são realizadas anualmente (dados de 2016). Ela está na lista dos 20 melhores hospitais da América Latina em 2014, em pesquisa realizada por um centro de pesquisa público da Espanha. $\mathrm{O}$ reconhecimento internacional é acompanhado de reconhecimento nacional. $\mathrm{O}$ caso $\mathrm{C}$ foi escolhido como modelo de gestão para os hospitais do Ministério da Educação.

A análise de conteúdo do caso $\mathrm{C}$ revelou outras categorias que destacam os princípios e os fatores motivadores da estrutura da governança (corporativa, de TI e da informação), considerando que a organização do caso $\mathrm{C}$ tem práticas e princípios formalizados de governança corporativa, de Tl e da Informação.

\begin{tabular}{|c|c|c|c|}
\hline & Governança Corporativa & Governança de $\mathrm{TI}$ & Governança da Informação \\
\hline Princípios & $\begin{array}{l}\text { Transparência } \\
\text { Prestação de contas }\end{array}$ & $\begin{array}{l}\text { Alinhamento com governança } \\
\text { corporativa } \\
\text { Transparência } \\
\text { Prestação de contas } \\
\text { Reconhecimento externo e interno }\end{array}$ & $\begin{array}{l}\text { Alinhamento com governança } \\
\text { corporativa e de TI } \\
\text { Transparência } \\
\text { Prestação de contas } \\
\text { Reconhecimento externo e interno }\end{array}$ \\
\hline $\begin{array}{l}\text { Fatores } \\
\text { Motivadores }\end{array}$ & $\begin{array}{l}\text { Transparência } \\
\text { Exigências de órgãos } \\
\text { públicos/reguladores } \\
\text { Priorização dos investimentos } \\
\text { Busca por melhores indicadores }\end{array}$ & $\begin{array}{l}\text { Reconhecimento externo e interno } \\
\text { Exigências de órgãos } \\
\text { públicos/reguladores } \\
\text { Melhorar a gestão de pessoas } \\
\text { Melhorar a gestão de projetos } \\
\text { Melhorar a gestão de contratos } \\
\text { Apoio à informação } \\
\text { Priorização dos investimentos } \\
\text { Busca por melhores indicadores }\end{array}$ & $\begin{array}{l}\text { Apoio à decisão } \\
\text { Melhorar o envolvimento de } \\
\text { informação com outras áreas do } \\
\text { negócio } \\
\text { Criação de políticas e normas } \\
\text { Monitoramento da informação } \\
\text { Suporte aos direitos decisórios } \\
\text { quanto à informação }\end{array}$ \\
\hline
\end{tabular}

Figura 5. Elementos resultantes da análise do caso $\mathrm{C}$

Fonte: Elaborada pelos autores (2018).

Os principais princípios de governança corporativa no caso $\mathrm{C}$ são a transparência e a prestação de contas. $\mathrm{A}$ governança de TI e a da informação, pelo alinhamento que têm com a governança corporativa, baseiam-se nos mesmos princípios. No caso C, há uma forte percepção da governança da informação como auxiliar na governança de Tl, 
a governança da informação é primordial também nesse processo, porque fazendo a gestão da informação e garantindo que ela chegue nos seus públicos adequados através das ferramentas adequadas, acho que é um fator primordial para a gente garantir a governança de $\mathrm{TI}(\mathrm{E} 2 \mathrm{C})$.

Consequentemente, a governança da informação também está alinhada à governança de $\mathrm{TI}$ no caso $\mathrm{C}$, logo os mesmos princípios da governança de TI são aplicados à governança da informação. Para o caso $\mathrm{C}$, esse fator diferenciador traz o reconhecimento interno e externo, motivando assim a própria estrutura de governança na organização e nas outras decisões quanto ao uso de TI na organização.

0 elemento de busca do reconhecimento externo/interno e o princípio de prestação de contas podem estar relacionados ao fato do hospital ser público, conforme Eeckloo et al. (2004), e em um hospital público não há acionistas, logo há a mudança da prestação de contas dos acionistas para os stakeholders do hospital. Assim, existe o desejo da administração de aumentar a visibilidade do hospital, demonstrando a sua forte governança, "por entender que hoje a sociedade tem o direito de saber o que é feito com os recursos públicos que são colocados aqui dentro" (E3C). Além do comentário, a matriz de relação entre os elementos, extraída do sistema de análise, mostra a proximidade entre os elementos de estrutura organizacional e prestação de contas, representada por uma circunferência maior do que as outras.

Essa busca por visibilidade também é citada por Álvares, Giacometti e Gusso (2008) como um dos fatores motivadores para a governança corporativa, bem como melhorar as práticas organizacionais. Essa melhora das práticas organizacionais também é vista no caso $\mathrm{C}$, e tanto nos fatores motivadores da governança corporativa (priorização dos investimentos e busca por melhores indicadores) como nos fatores motivadores da governança de $\mathrm{TI}$ (melhorar a gestão de pessoas, projetos e contratos, bem como a priorização dos investimentos e a busca por melhores indicadores).

Além de influenciar nos indicadores, as características da organização também influenciam a dimensão de governança da informação (Weber et al., 2009; Panian, 2010; Khatri \& Brown, 2010). No caso C, os elementos que se destacaram em governança da informação foram: envolvimento com as áreas de negócio, informação no processo decisório, direitos decisórios e políticas e normas da organização. Para Panian (2009), a governança de dados envolve todos dentro da organização e deve estar relacionada com praticamente todos os projetos da organização, enquanto a informação for considerada um ativo crítico na organização. Assim, não é surpresa que a governança da informação "ainda está espalhada [na organização]" (E1C).

O elemento de políticas e normas é o elemento mais citado na dimensão de governança da informação. No caso $\mathrm{C}$, as políticas e as normas quanto ao uso da informação de pacientes estão bem reguladas, sendo apoiadas por duas estruturas na organização: a Comissão de Prontuários e pelo Serviço de Arquivo Médico de Informações de Saúde. Porém há a falta de maior regulamentação nas informações administrativas e ainda há muitas políticas que estão no "eu acho que é mais tácita do que escrita" (E2C). Mas "tem um movimento para acontecer" (E1C).

A relação entre governança da informação e processo decisório também foi observada no caso $C$, "a informação é saber, se a informação é poder, quanto mais domínio que eu tiver daquilo, mais eu vou ter segurança nas decisões que eu vou tomar naquelas alternativas que me apresentarem" (E1C). Além disso, houve a menção de um intermediário nessa relação, o conhecimento, "acho que a informação é um dos pilares para gerar conhecimento e desse conhecimento tomar a decisão" (E3C).

\subsection{Análise Comparativa entre os Estudos de Casos}

Com base nos resultados da pesquisa, foi possível realizar um comparativo entre as estruturas de governança dos três casos. Em todos os casos foi possível perceber uma maior ênfase e desenvolvimento nos elementos relacionados à Governança da Informação, tendo em vista que a adoção da mesma é a mais recente e, por isso, está em maior evidência nas organizações pesquisadas. No caso $\mathrm{A}$, ainda não há uma estrutura de governança da informação, com normas e controles de responsabilidades, porém há a percepção de que não existem fronteiras entre o framework de governança de TI e o de governança da informação. Importante mencionar que está ocorrendo a implantação de um framework de governança de TI, logo se espera que, por não haver a percepção de fronteiras, formalizem-se alguns dos elementos de governança da informação. 


\begin{tabular}{|l|l|l|l|}
\hline & Governança Corporativa & Governança de TI & Governança da Informação \\
\hline Princípios & Transparência & Alinhamento com governança & Alinhamento com governança \\
& Prestação de contas & corporativa & Transparência \\
& Responsabilidade Corporativa & Transparência & Prestação de contas \\
& & Prestação de contas & Responsabilidade Corporativa \\
& & Reconhecimento externo e interno & Reconhecimento externo e interno \\
\hline Fatores & Transparência & Transparência & Transparência \\
& Prestação de contas & Prestação de contas & Prestação de contas \\
& Responsabilidade Corporativa & Responsabilidade Corporativa & Responsabilidade Corporativa \\
& Exigências de órgãos & Exigências de órgãos & Exigências de órgãos \\
& públicos/reguladores & públicos/reguladores & públicos/reguladores \\
& Exigências internas/padrões & Exigências internas/padrões & Exigências internas/padrões \\
& Estrutura organizacional & Estrutura organizacional & Estrutura organizacional \\
& Gestão de riscos & Gestão de riscos & Monitoramento da informação \\
& Busca por melhores indicadores & Apoio ao negócio & Gestão de riscos \\
& Priorização dos investimentos & Apoio à informação & Apoio ao negócio \\
& & Melhorar a gestão de pessoas & Apoio à decisão \\
& & Melhorar o envolvimento de \\
& & Melhorar a gestão de projetos & informação com outras áreas do \\
& & Melhorar a gestão de contratos & negócio \\
& & & Criação de políticas e normas \\
\hline
\end{tabular}

\section{Figura 6. Elementos resultantes da análise dos três casos}

Fonte: Elaborada pelos autores (2018).

No caso $C$ já há normas e controles de responsabilidade que visam ao valor, à qualidade e ao compliance da informação no ambiente informacional da organização (conceito de governança da informação), entretanto existem diferentes percepções quanto ao tamanho da fronteira entre a governança de TI com a governança da informação, mas há a existência de uma fronteira.

No caso $B$, em que há um departamento responsável pela governança do ambiente informacional, talvez por ser recente, existem diferenças nas respostas quanto à estrutura do gerente de governança de $\mathrm{Tl}$ e da gerente do ambiente informacional. Enquanto a última acredita que não há fronteira, respondendo apenas à governança corporativa, o gerente de governança de TI acredita que, com o COBIT, pode-se monitorar a governança da informação. Essas diferenças confirmam conclusões de Weber et al. (2009), que apontam para a necessidade de o framework de governança da informação atender às necessidades da organização, ou seja, não há um modelo único para governança da informação.

Os fatores motivadores já foram discutidos nas análises de cada caso, mas se ressalta a grande quantidade de fatores motivadores para a governança da informação. Essa é mais uma evidência da importância da governança da informação nas organizações, em especial a preocupação das organizações em extrair valor desse fluxo informacional que justifique o investimento necessário para lidar com uma grande quantidade de dados heterogêneos presentes hoje nas organizações.

\section{CONSIDERAÇÕES FINAIS}

O objetivo dessa pesquisa foi analisar os princípios e os fatores motivadores que auxiliam as organizações no processo de adoção da governança corporativa, de TI e da Informação. Essas relações foram identificadas nos estudos de casos nas figuras resumos expostos nas Figuras 3 (caso A), 4 (caso B), 5 (caso C). Na Figura 6, foi apresentada a composição com todos os estudos de casos. As relações foram descritas nas Figuras 3 (apenas do caso A), 4 (apenas do caso B), 5 (apenas do caso C) e na Figura 6, com a união de todos os estudos de casos.

Ao contrário do presente na literatura disponível (e.g. Tallon et al., 2013), os estudos de casos revelam que não há uma estrutura ideal para governança, cada caso possui relações únicas, sendo que os casos não apresentaram consenso na relação entre governança de Tl e da informação. Apesar disso, há sim um consenso de que essas duas devem estar alinhadas com a governança corporativa da organização, respondendo às necessidades da mesma. 
Ainda que muitas pesquisas negligenciam que diferentes fatores contingenciais afetam aos diferentes ambientes informacionais das organizações, logo a estrutura de governança da informação deve ser desenhada de acordo com cada organização. Consequentemente, não se pode apontar uma estrutura única de governança da informação para comparação dos casos.

Além dos elementos revelados nos estudos de casos, a pesquisa acrescenta informações na ainda incipiente literatura sobre o tema no Brasil e acrescenta uma pesquisa empírica à literatura mundial (que também é escassa de estudos empíricos).

Os benefícios da pesquisa, para as organizações, são os elementos encontrados nos estudos de casos, que podem auxiliar organizações a implantar novos modelos de governança da informação, adaptados a suas estruturas organizacionais. Também como benefício, a comparação e a análise das estruturas de governança, que auxiliam consultores a definirem os elementos mais adequados para cada organização.

Dentre as limitações dessa pesquisa, destaca-se o fato de que o estudo foi pontual, acredita-se que uma pesquisa com um corte longitudinal acrescentaria mais elementos e poderia aumentar o poder explicativo de cada elemento e dimensões encontradas e, além disso, o fato de ser uma pesquisa qualitativa, os resultados dizem respeito somente aos contextos analisados.

Por fim, visando a pesquisas futuras, sugere-se analisar em profundidade 0 valor da informação nas organizações em seus três elementos: compartilhamento de informações, satisfação do usuário e obtenção de valor. Como há uma lacuna de pesquisas sobre o tema, propõe-se realizar um comparativo entre empresas filiais e matrizes, verificando diferenças em seus ambientes informacionais, com possivel utilização de variáveis de controle, como distância e localização geográfica entre unidades, estrutura e tamanho organizacional e até a própria cultura do país em que está inserida a filial ou a matriz; e, finalmente, seria possível verificar se a dissonância entre a relação governança de TI e governança da informação tem relação com os frameworks de governança de TI implantados.

\section{REFERÊNCIAS}

Álvares, E., Giacometti, C., \& Gusso, E. (2008). Governança corporativa: um modelo brasileiro. Elsevier.

Ammann, M., Oesch, D., \& Schmid, M.M. (2011). Corporate governance and firm value: International evidence. Journal of Empirical Finance, 18(1), 36-55.

Bala, S. (2018) Information Management: Transforming for the digital era to retain Competitive relevance. IDC White Paper, June 2018.

Bernroider, E. W. (2008). IT governance for enterprise resource planning supported by the DeLone-McLean model of information systems success. Information \& Management, 45(5), 257-269.

Bardin, L. (2004). Análise de conteúdo. Lisboa: Martins Fontes.

Bharadwaj, A., El Sawy, O. A., Pavlou, P.A., \& Venkatraman, N. (2013). Digital business strategy: toward a next generation of insights. MIS quarterly, 471-482.

Bhat, G., Hope, O.K., \& Kang, T. (2006). Does corporate governance transparency affect the accuracy of analyst forecasts?. Accounting \& Finance, 46(5), 715-732.

Bauer, M.W. (2002). Análise de conteúdo clássica: Uma revisão. In: Bauer, Martin W.; Gaskell, George (org.). Pesquisa qualitativa com texto, imagem e som: Um manual prático. Petrópolis: Vozes.

Biernacki, P., \& Waldorf, D. (1981). Snowball sampling: Problems and techniques of chain referral sampling. Sociological Methods \& Research, 10(2).

Bowen, P.L., Cheung, M.-Y. D., \& Rohde, F.H. (2007). Enhancing IT governance practices: A model and case study of an organization's efforts. International Journal of Accounting Information Systems, 8. 
Brand Finance. (2019). Brand finance banking 500. Brand Finance. Disponivel em: https://brandfinance.com/images/upload/banking_500_2019_locked.pdf. Acesso em: 25 fev. 2019.

Brown, A.E., \& Grant, G.G. (2005). Framing the frameworks: A review of IT governance research. Communications of the Association for Information Systems, 15(1), 38.

Bushman, R.M., \& Smith, A.J. (2001). Financial accounting information and corporate governance. Journal of Accounting and Economics, 32.

Calder, A. (2008). IT Governance Overview. In: Tarantino, Anthony (Ed.). Governance, Risk and Compliance Handbook. Hoboken, N.J.: John Wiley.

Carvalho, D.B., \& Caldas, M.P. (2006) Basiléia Il: Abordagem prática para acompanhamento de risco operacional em instituições financeiras. Resenha BM\&F Brasil, (169).

Cherman, A., \& Tomei, P.A. (2005). Códigos de ética corporativa e a tomada de decisão ética: instrumentos de gestão e orientação de valores organizacionais?. Revista de Administração Contemporânea, 9(3), 99-120.

Chhaochharia, V., \& Laeven, L. (2009). Corporate governance norms and practices. Journal of Financial Intermediation, 18(3), 405-431.

Coyne, E.M., Coyne, J.G., \& Walker, K.B. (2018). Big Data information governance by accountants. International Journal of Accounting \& Information Management, 26(1), 153-170.

Cooney, J.P. (1991). Qual o real valor da informação? Revista Escola de Biblioteconomia UFMG, 20(2).

Davenport, T.H., \& Brooks, J.D. (2004). Enterprise systems and the supply chain. Journal of Enterprise Information Management, 17(1), 8-19.

Datskovsky, G. (2009). Information governance. In: Lamm, Jacob. Under control: Governance across the enterprise. New York: Apress.

De Abreu, F.F., Maçada, A.C.G., \& Kumar, K. (2013). Information governance in the banking industry. In 2013 46th Hawaii International Conference on System Sciences (pp. 4436-4445). IEEE.

De Haes, S., \& Van Grembergen, W. (2015). Enterprise Governance of IT. In Enterprise Governance of Information Technology (pp. 11-43). Springer, Cham.

Eeckloo, K., Herk, G.V., Hulle, C.V., \& Vleugels, A. (2004). From corporate governance to hospital governance: Authority, transparency and accountability of Belgian non-profit hospitals' board and management. Health Policy, 68.

Faria, F.D.A. (2010). Análise do impacto dos investimentos em TI no resultado operacional dos bancos brasileiros.

Faria, F. De A., Macada, A.C.G., \& Kumar, K. (2017). Modelo Estrutural de Governança da Informação para Bancos. Rev. adm. empres., 57(1), 79-95.

Franco, M.L.P.B. (2008). Análise de conteúdo. Brasília: Liber Livro.

Frezatti, F., Rocha, W., Nascimento, A. R., \& Junqueira, E. (2009) Controle gerencial: Uma abordagem da contabilidade gerencial no contexto econômico, comportamental e sociológico. São Paulo: Atlas.

Gianella, S., \& Gujer, W. (2006). Improving the information governance of public utilities through an organizational knowledge base. In: World Congress On Engineering Asset Management, 2006, Queensland. Proceedings of World Congress On Engineering Asset Management Queensland. 
Gompers, P., Ishii, J., \& Metrick, A. (2003). Corporate governance and equity prices. The quarterly journal of economics, 118(1), 107-156.

Hamaker, S. (2003). Spotlight on governance. Information Systems Control Journal, 1(1).

Hamaker, S., \& Hutton, A. (2003). Principles of IT governance. Information Systems Control Journal, 2, 47-50.

Hutchinson, M., \& Gul, F. A. (2004). Investment opportunity set, corporate governance practices and firm performance. Journal of corporate finance, 10(4), 595-614.

Kanagaretnam, K., Lobo, G. J., \& Whalen, D. J. (2007). Does good corporate governance reduce information asymmetry around quarterly earnings announcements?. Journal of Accounting and Public Policy, 26(4), 497-522.

Khatri, V., \& Brown, C. (2010). Designing data governance. Communications of the ACM, 35(1).

Kooper, M.N., Maes, R., \& Lindgreen, E.E.O. (2011). Roos. On the governance of information: Introducing a new concept of governance to support the management of information. International Journal of Information Management, 31.

Larsen, M.H., Pedersen, M.K., \& Andersen, K.V. (2006, January). IT governance: reviewing 17 IT governance tools and analysing the case of Novozymes A/S. In Proceedings of the 39th Annual Hawaii International Conference on System Sciences (HICSS'06) (Vol. 8, pp. 195c-195c). IEEE.

Laville, C., \& Dionne, J. (1999). A construção do saber: Manual de metodologia da pesquisa em ciências humanas. Porto Alegre: Artmed.

Luciano, E.M., \& Testa, M.G. (2011). Controles de governança de tecnologia da informação para a terceirização de processos de negócio: Uma proposta a partir do COBIT. JISTEM J.Inf.Syst. Technol. Manag. (Online), 8(1).

Lunardi, G.L., Becker, J.L., \& Maçada, A.C.G. (2014). The impact of adopting IT governance on financial performance: An empirical analysis among Brazilian firms. International Journal of Accounting Information Systems, 15(1), 66-81.

De Mendonça, A. R. R. (2004). O Acordo da Basiléia de 2004: Uma Revisão Em Direção Às Práticas de Mercado. Recuperado em 25 fev., 2019, de http://www.eco.unicamp.br/docprod/downarq.php?id=47\&tp=a.

Mikalef, P., Pappas, I. O., Krogstie, J., \& Giannakos, M. (2017). Big data analytics capabilities: a systematic literature review and research agenda. Information Systems and e-Business Management, 1-32.

Oliveira, M., Maçada, A. C. G., \& Goldoni, V. (2009). Forças e fraquezas na aplicação do estudo de caso na área de sistemas de informação. Revista de Gestão, 16(1).

Panian, Z. (2012). Some practical experiences in data governance. World Academy of Science, Engineering and Technology, 62.

Patton, M.Q. (2002). Qualitative research \& evaluation methods. Thousand Oaks: Sage Publications.

Petty, N.J., Thomson, O.P., \& Stew, G. (2012). Ready for a paradigm shift? Part 1: Introducing the philosophy of qualitative research. Manual Therapy, 17.

Sohal, A.S., Fitzpatrick, P. (2002). IT governance and management in large Australian organisations. International Journal of Production Economics, 75.

Tallon, P., Ramirez, R., \& Short, J. (2013). The Information Artifact in IT Governance: Toward a Theory of Information Governance. Journal of Management Information Systems. 30(3), 141-178.

Trites, G. (2004). Director responsibility for IT governance. International Journal of Accounting Information Systems, 5(2), 89-99. 
Van Grembergen, W., \& Haes, S. (2009). Enterprise Governance of Information Technology. New York: Springer.

Van Grembergen, W., \& De Haes, S. (2009). Enterprise governance of information technology: achieving strategic alignment and value. Springer Science \& Business Media.

Van Grembergen, W., \& De Haes, S. (2018). Introduction to the Minitrack on IT Governance and its Mechanisms.

Vatharkar, S., Gao, P., \& Fomin, V. (2018). Factors Affecting Business and Information Technology Alignment at the Lower Levels of a Public Organisation. International Journal of Healthcare Information Systems and Informatics (IJHISI), 13(3), 35-48.

Vergara, S.C. (2009). Métodos de coleta de dados no campo. São Paulo: Atlas.

Weber, K. et al. (2009). One size does not fit all - a contingency approach to data governance. ACM Journal of data and information quality, 1(1).

Weill, P., \& Ross, J.W. (2006). Governança de tecnologia da informação: Como as empresas com melhor desempenho administram os direitos decisórios de TI na busca por resultados superiores. São Paulo: McBooks.

Weill, P., \& Ross, J.W. (2009). IT Savvy: What top executives must know to go from pain to gain. Boston: Harvard Business Press.

Wende, K. (2007). A model for data governance: Organising accountabilities for data quality management. In: Australasian Conference on Information Systems, 18, 2007, Toowoomba. Proceedings of Australasian Conference on Information Systems. Toowoomba.

Yin, R.K. (2005). Estudo de caso: Planejamento e métodos. Porto Alegre: Bookman. 